Topic : Disaster Management

\title{
Portable Photovoltaic Powerplant with Solar Tracker for Disaster Affected Area Emergency Power Supply
}

\author{
Indra Riyanto ${ }^{a *}$, Ade Octaviano $^{a}$, Suparmoko ${ }^{a}$, Kozo Obarab \\ aCenter for Environmental Studies Budi Luhur University, Jl. Cileduk Raya No. 99 Jakarta \\ Selatan 12260, Indonesia \\ ${ }^{b}$ Institute for Sustainable Development Kagoshima University, Korimoto-cho, Kagoshima, \\ Japan
}

\begin{abstract}
This paper will discuss about the design of a portable photo voltaic electric generator capable of tracking sunlight in all directions. Such power generator is designed for disaster affected area with power outage, such as during major floods like Jakarta in 2012, or strong earthquake such as Yogyakarta in 2006 and Japan in 2011 (Tohoku) and 2016 (Kumamoto). Such occurence usually results in disruptions of public service, especially power grids. The system consists of a $10 \mathrm{Wp}$ PV solar panels capable in two axes movement, which is $120^{\circ}$ horizontal and $360^{\circ}$ azimuth movement with ATMega8535 micro controller as the main controller. Two-axis movement is based on two types of sensors, $360^{\circ}$ directional movement is based on the HMC5883 compass sensor. This compass sensor panel also be configured to always directs towards the sun so that if the direction of the base plate was changed, it will automatically direct the panel to the direction of the sun. While $120^{\circ}$ vertical movement based on three pieces of LDR (Light Dependent Resistor) as sun sensors. The purpose of this system is to maximize the amount of light received by the panel so the panel power output is also maximized so it can generate emergency electrical supply for lighting and other basic needs.
\end{abstract}

\section{Keywords}

Disaster area; Solar Panel; Solar Tracker; Inverter; Emergency Power Generation

\section{Introduction}

The use of alternative energy as a power plant lately much discussed, the use of alternative energy is generated by increasing the amount of electrical energy needs. One of the much talked about alternative energy is sunlight. Utilization of sunlight as electrical energy is done by utilizing the so-called solar cell or solar panel. The use of solar panels has been widely used as, for example, street lighting, but the installation of solar panels mostly is made static so that when the sun is not perpendicular to the surface of the panel generated power panels are also less than maximum. This makes the installation of solar panels began to be equipped with a mechanical light tracking,

\footnotetext{
${ }^{*}$ Corresponding author. Tel.: +62-815-900-2864; fax: +62-21-737-1164.

E-mail address:indra.riyanto@budiluhur.ac.id
} 
but the movement of the system is only $180^{\circ}$ in one axis or as a half circle (Tudorache, 2010) and (Balabel, 2013) with the convex part above, so the placement of this system must always be under the path of the sun's rotation. While others also experimented with two axis movement, most if not all is still designed for fixed location such as in India (Deb, 2012) and (Dhanabal, 2013), Iran (Bazyari, 2014).

The design aims to complement the mechanical movement of the solar panels into two axes: $120^{\circ}$ in vertical axis and $360^{\circ}$ azimuth. The movement of the system can be simulated as a hemispherical shape. It is intended that the sunlight is always perpendicular to the surface of the photovoltaic panel.

\section{System Design}

The proposed design is using microcontroller ATMega8535 as the main controller system, two DC motor as the mechanical panel adjuster, compass sensors as position sensors and LDR sensor panels as the vertical axis movement sensor.

After the system start-up, the microcontroller is waiting for the input command to select either automatic or manual mode. If the system is in automatic mode, then the microcontroller will read through the position of the horizontal axis compass sensor to check if the system is already aligned to the direction of the sun or not. If the position is not aligned, then the microcontroller commands the horizontal axis motor to rotate the panels so it is facing to the east. When the east-facing position is achieved, then the microcontroller will read the ADC value from the three LDR light sensors to determine the incident angle of sunlight. The photovoltaic (PV) panel will be facing east if the value of the East LDR is larger than the Center and West LDRs, the PV panel will be tilted towards the west if the ADC value of West LDR is greater than the value of the other two LDRs. However, the position of the vertical axis of the panel will be facing up $\left(90^{\circ}\right.$ angle of sunrise) if the value of the East and Center LDRs is greater than the West LDR or when Center and West LDRs greater than East LDR. After panel angle has been achieved, microcontroller will read battery voltage by Zener diode sensor. If the battery in full condition then the microcontroller will switch on the inverter so in this case the load will also be controlled by reading the value of the load, when the load exceeds the inverter output, microcontroller will display "over-load" alert on LCD and disconnect the system temporarily to prevent excessive usage.

\subsection{LDR Light Sensor Schematics}

Solar tracking system design uses LDR as sensors. LDR will be assembled using a voltage divider as shown in Figure 1.

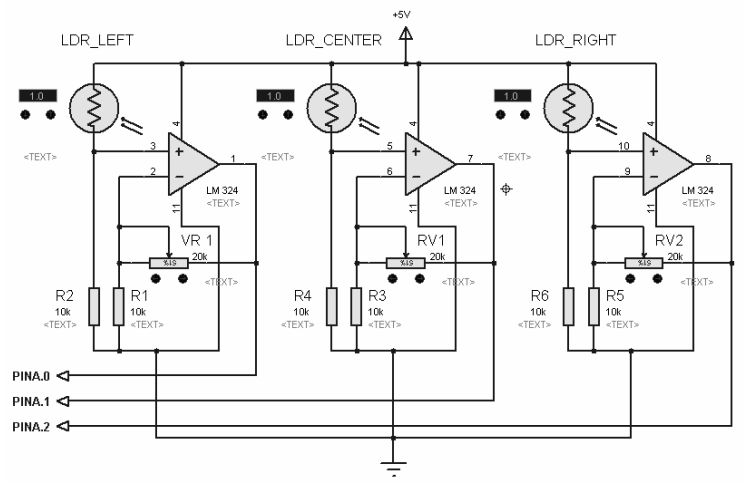

Figure 1. Light sensor schematics

\subsection{Battery Charging}

This circuit uses a relay as the main switch when the battery is fully charged; when the battery is not full then the relay will be off or be in a position normally closed. Sensor for the battery charge is a $12 \mathrm{~V}$ Zener D1, so when the battery was full the Zener 
diode will switch the base of the transistor Q2. Q2 is used as an electrical switch that will function to switch ground current from R2, which will light up the LED indicator and will read a logic 0 on microcontroller's C.7 pin. When C.7 pin in the microcontroller receives logic 0 then the microcontroller will turn on the rightmost relay 1 to be opened up to D1, which normally do not receive the voltage of over $12 \mathrm{~V}$.

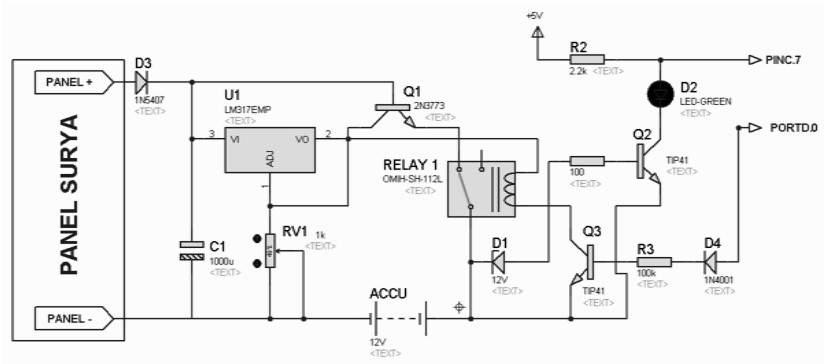

Figure 2. Battery charging schematics

\subsection{Inverter}

Inverters used here is a 4047 IC, MOSFET transistors, 5A transformer, and relays. IC 4047 is used as a square wave generator which will switch the MOSFET transistor IRF540N to perform the push pull transformer, using the MOSFET type transistor inverter is expected to be able to bear loads up to 150 watts. Relay on the inverter is used as switch when battery condition has not yet reached the minimum charge or fully charged the inverter can not be switched on. Figure 3 shows the inverter's schematics.

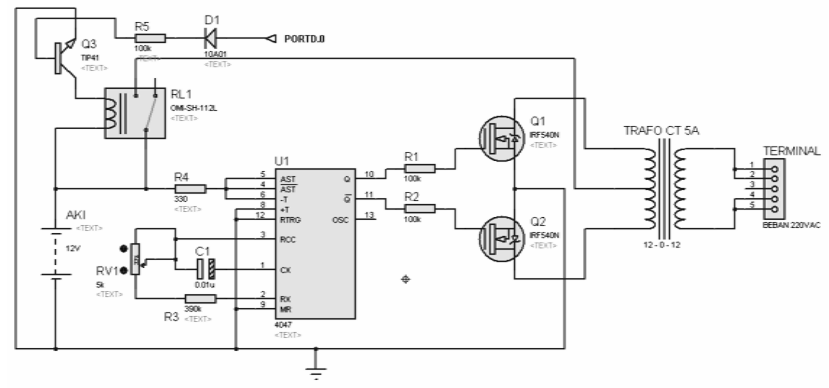

Figure 3. Inverter circuit schemamitcs

\section{Testing And Analysis}

\subsection{LDR Light SensorTesting}

Testing the sunlight sensor circuit using LDR is done by measuring the voltage at the output of the LM324 which will go into the microcontroller ADC PORT ATMega8535. Table 1 shows the test results.

Table 1. Light Sensor Testing Results

\begin{tabular}{lllllll}
\hline \multirow{2}{*}{ Time } & \multicolumn{3}{c}{$\mathbf{V}_{\text {out }}$ LDR (volt) } & \multicolumn{3}{c}{ Vout $_{\text {L }}$ LM24 (volt) } \\
\cline { 2 - 7 } & East & Center & West & East & Center & West \\
\hline \multirow{2}{*}{$09.00-$} & & & & & & \\
15.00 & 5.3 & 4.93 & 4.98 & 4.47 & 4.5 & 4.3 \\
& & & & & & \\
\hline
\end{tabular}

\subsection{Inverter Testing}

DC to AC inverter testing is done by providing a direct current voltage of 12 volts. In order for $\mathrm{DC}$ to $\mathrm{AC}$ inverter circuit of 150 watts to work, the voltage supplied 12 volts, 
and the output section connected by a digital voltmeter and digital ammeters. IC CD4074 is used as a generator. The following Table 2 shows the result of testing 150 watt inverter using a load of three light bulbs of 23 watts each.

\begin{tabular}{llll}
\multicolumn{4}{c}{ Table 2. Inverter Testing Result } \\
\hline \multirow{2}{*}{ Battery status } & \multicolumn{3}{c}{ Load Stats } \\
\cline { 2 - 4 } & Load 1 & Load 2 & Load 3 \\
\hline 13,6 volt & ON & ON & ON \\
\hline 11.2 volt & ON & OFF & OFF \\
\hline
\end{tabular}

\subsection{Solar Cell module Testing}

Solar cell testing was conducted from 09:00 to 15:00 with direct measuring of the output voltage on the poles of the solar cell module. Figure 4 shows the measurement scheme and Table 3 shows the measurement result.

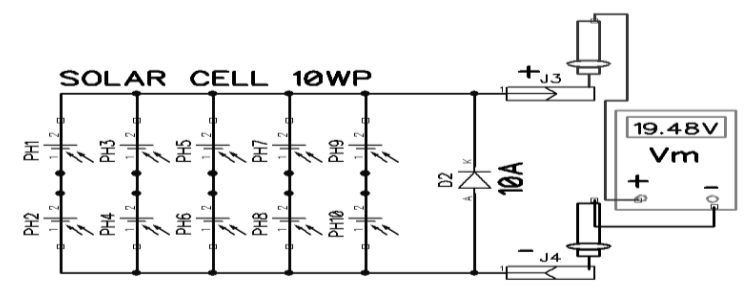

Figure 4. Solar cell module Vout measurement

Table 3. Solar cell module Vout measurement result

\begin{tabular}{|c|c|c|c|}
\hline Time & $\begin{array}{c}\text { Vout }_{\text {Out }} \\
\text { (Volts) }\end{array}$ & $\begin{array}{c}\text { Sun } \\
\text { Elevation } \\
\text { (Degrees) }\end{array}$ & $\begin{array}{c}\text { Panel } \\
\text { Position }\end{array}$ \\
\hline 09.00 & 19.05 & $45^{\circ}$ & \multirow{4}{*}{ East } \\
\hline 09.30 & 19.20 & $52,5^{\circ}$ & \\
\hline 10.00 & 19.40 & $60^{\circ}$ & \\
\hline 10.30 & 18.89 & $57,5^{\circ}$ & \\
\hline 11.00 & 19.97 & $75^{\circ}$ & \multirow{5}{*}{ Center } \\
\hline 11.30 & 20,3 & $82,5^{\circ}$ & \\
\hline 12.00 & 20,52 & $90^{\circ}$ & \\
\hline 12.30 & 20,5 & $97,5^{\circ}$ & \\
\hline 13.00 & 20.72 & $105^{\circ}$ & \\
\hline 13.30 & 18.85 & $112,5^{\circ}$ & \multirow{4}{*}{ West } \\
\hline 14.00 & 20.02 & $120^{\circ}$ & \\
\hline 14.30 & 18.22 & $127,5^{\circ}$ & \\
\hline 15.00 & 20.35 & $135^{\circ}$ & \\
\hline
\end{tabular}

Photovoltaic Panel output shows that $\mathrm{V}_{\text {out }}$ is stable near maximum of 20 Volts, except for some drops due to cloud cover. Comparison of the output between static and tracker-equipped PV Panel is shown in Figure 5. 


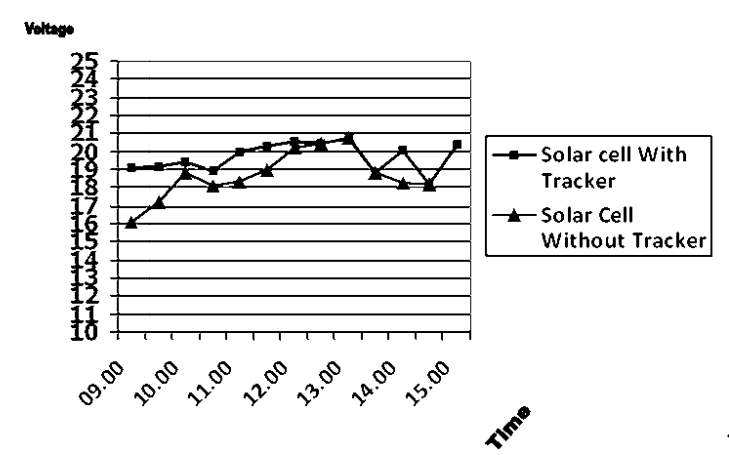

Figure 5. Static and Tracker-equipped panel Vout comparison

\section{Discussion}

Testing of the completely assembled component focused on the mount with the goals is:

- When the base plate's direction is changed, the panel mount could align itself to the east,

- The panel could trace the elevation of the sun,

- Inverter can support loads,

- Source select switch work properly during overload

From the testing, the base plate can align itself facing toward East direction by 5 degrees per second. Static panel output measured at 16 Volts in the morning compared to 19 Volts when equipped with tracker with both peaked at around 20 to 21 Volts during mid-noon, and then static panel starts to drop again after 13.00 while tracker equipped panel can maintain a steady output voltage.

Calculation for the performance of the system yields the result:

$$
\begin{array}{lll}
\text { Battery Capacity } & =12 \mathrm{~V}, 5 \mathrm{Ah} & \\
\text { Load }(\mathrm{Pl}) & =46 \mathrm{~W} & (2 \times 23 \mathrm{~W}) \\
\text { Load Voltage }(\mathrm{Vl}) & =220-240 \mathrm{~V} & \\
\text { Load current }(\mathrm{Il}) & =1.13 \mathrm{~A}
\end{array}
$$

Then the load bearing duration (T):

$$
\begin{aligned}
\text { Load duration }(\mathrm{T}) & =5 \mathrm{Ah} / 1.13 \mathrm{~A} \\
& =4,4 \text { hours (for two lamps @ 23W each) }
\end{aligned}
$$

Load testing of the inverter and battery with loads of up to 46 Watts, simulated by a pair of 23W lamps, the stored energy can support the load for over 4 hours. Theoretically, this can last for 5 hours if fully discharged, but the inverter itself also needs energy and will cease functioning when the voltage drops below 9 Volts. This is required to generate square wave for triggering the transistor to perform push-pull and convert DC output from the panel and battery to AC for the load.

\section{Conclusion}

After the test has been completed, conclusion can be drawn as follows:

- The solar tracker can track the position of sun in horizontal plane (azimuth) and in vertical plane (elevation)

- Tracker can maintain the output of solar panel by align it perpendicular to the direction of incident sunlight 
- This tracker is especially designed to be lightweight for portable use on emergency units and may be useful other mobile platforms

\section{References}

Balabel, A., et al. (2013). Design and Performance of Solar Tracking Photo-Voltaic System; Research and Education. International Journal Of Control, Automation And Systems. Vol.1 No.2. pp.49-55

Bazyari, S., et al. (2014). A Study on the Effects of Solar Tracking Systems on the Performance of Photovoltaic Power Plants. Journal of Power and Energy Engineering, Vol. 2 No. 2. pp.718728

Deb, G., Roy, A.B. (2012). Use of Solar Tracking System for Extracting Solar Energy. International Journal of Computer and Electrical Engineering, Vol.4, No.1. pp.42-46

Dhanabal, R., et al. (2013). Comparison of Efficiencies of Solar Tracker systems with static panel Single-Axis Tracking System and Dual-Axis Tracking System with Fixed Mount. International Journal of Engineering and Technology. Vol. 5, No. 2. pp.1925-1933

Tudorache, T. (2010). Design of a Solar Tracker System for PV Power Plants. Acta Polytechnica Hungarica. Vol. 7, No. 1. pp.23-39. Hungary. 